\title{
Chapter 15 \\ Mediation and Conciliation in Collective \\ Labor Conflicts in Europe: A Cross \\ Cultural Analysis
}

\author{
Patricia Elgoibar, Francisco J. Medina, Ana Garcia, Erica Romero Pender \\ and Martin C. Euwema
}

\subsection{Commonalities and Differences Among Member States}

Mediation and conciliation appear to be effective tools, both for the prevention and regulation of collective labor conflicts. Along this handbook the systems and the perceptions of users and mediators from 12 European countries (all EC member states) are presented. In this chapter we aim at a cross cultural analysis through the comparison of these various systems.

As discussed in Chap. 1, article 3 of the Directive 2008/52/EC of the European Parliament and the Council of the 21st of May of 2008 (European Union Directive on mediation) states: "Mediation means a structured process, however named or referred to, whereby two or more parties to a dispute attempt by themselves, on a voluntary basis, to reach an agreement on the settlement of their dispute with the assistance of a mediator. This process may be initiated by the parties or suggested or ordered by a court or prescribed by the law of a Member State". This mediation directive has as objective the facilitation of access to ADR and the promotion of the amicable settlement of disputes, by the promotion of the use of mediation as well as of a balanced relationship between mediation and judicial proceedings (European Commission, 2016). The EC recognizes member states have different traditions and systems, and implementation therefore takes different forms in the countries (Garriga, 2018). Given these, variety it will not come as a surprise that also mediation for collective labor conflicts is showing highly idiosyncratic practices and outcomes.

F. J. Medina · A. Garcia $\cdot$ E. R. Pender $(\bowtie)$

University of Seville, Seville, Spain

e-mail: ericaromeropender@gmail.com

P. Elgoibar

University of Barcelona, Barcelona, Spain

M. C. Euwema

University of Leuven, Leuven, Belgium

(C) The Author(s) 2019 
With well-established practices and effective outcomes in some, and with clear challenges in other countries, many of whom having a short tradition in mediation in general, and in collective labor conflicts specifically. Despite the differences, there are fundamental rights that must be taken into account in all member states. These are established in the European Social Charter (1996). In its article 6 about the right to bargain collectively, the charter indicates: "With a view to ensuring the effective exercise of the right to bargain collectively, the Parties undertake (...) the establishment and use of appropriate machinery for conciliation and voluntary arbitration for the settlement of labour disputes" (Council of Europe, 1996, p. 5). The EU Charter may have an impact on different normative systems of the member states (Eurofound, 2010).

This chapter first presents commonalities and differences in the legal and structural arrangements of the national systems when it comes to mediation in collective labor conflicts. Next, the perceptions of users and mediators are analyzed, and lastly the main challenges and recommendations for further developments in Europe are explored. Each country's system is considered as a unique case. We followed methods of qualitative multi-case analyses (Yin, 2009).

\subsection{Diversity in Regulations and Systems for Conciliation and Mediation in the EC}

This section explores the main commonalities and differences in regulations for and organization of mediation. These are presented in Table 15.1. Here we discuss some key features: (a) the obligation to use mediation; (b) providers of conciliation and mediation services and costs; (c) who act as mediators; (d) conflict parties or representatives at the table; (e) mediating different types of conflict; (f) phase in which the system is activated; ( $\mathrm{g}$ ) how to mediate: from evaluative to transformative mediation; (h) measuring effectiveness.

\section{(a) Obligation to conciliation or mediation}

To what extent is mediation mandatory to conflicting parties? For collective conflicts, this is particularly under ongoing debate in many countries in relation to the right for social actions, such as strikes. Do parties first have to try to solve their dispute through mediation, or at least a formal attempt to do so, before going to action? Plurality is the dominant trend in the EC in this respect (Valdes Dal-Re, 2003). In the application of the EC mediation directive, four different models of mediation are presented:

Model 1-Full Voluntary Mediation: the parties can engage a mediator to facilitate the resolution of any dispute that they have not been able to settle for themselves. In this case, a legal framework for mediation is not even required. 
15 Mediation and Conciliation in Collective Labor Conflicts ...

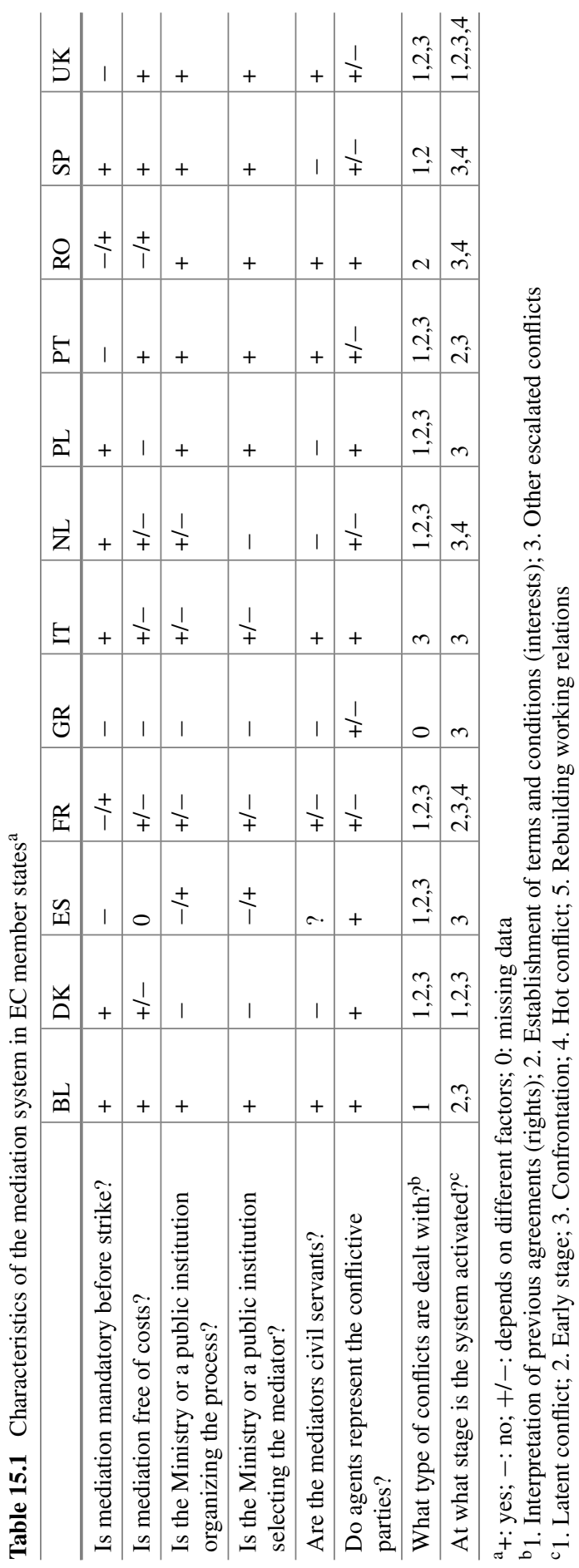


Model 2-Voluntary Mediation with Incentives and Sanctions: the parties are encouraged to have recourse to mediation, thus fostering the practice. This model requires a mediation law in place.

Model 3-Required Initial Mediation Session: the parties are required to attend an initial meeting with a mediator, free or at a moderate fee, to establish the suitability of mediation. This model, too, requires a legal framework regarding mediation.

Model 4-Full Mandatory Mediation: the parties must go through a full mediation procedure as a prerequisite to going to court, or to take actions such as strikes. The mandatory aspect applies only to attending the full procedure, while the decision to reach a settlement is always voluntary.

These four models have been applied differently throughout the EU for many different areas of mediation. Analysis of the four models in these other areas for mediation, shows that Model 3, the Required Initial Mediation Session, combines the most effective elements of both the voluntary and the mandatory models (De Palo \& Trevor, 2016). The question remains to what extent this conclusion also holds for collective labor conflicts. That is, for example, the requirement to do an attempt for mediation, before a strike or lock-out is legitimate.

Table 15.1 indeed offers a spectrum of levels in which mediation (or conciliation) is mandatory. Please note, that in many countries a first step is defined as conciliation, followed by mediation. Conciliation is often more informal, and corresponding with Model 1 (voluntary). However, also the second step of mediation can still be voluntary. For example ACAS in the UK offers its conciliation and mediation services on a completely voluntary basis. As does the SER in the Netherlands. In both countries, employees can go on strike without further notice or attempt to previously mediate.

These practices differ largely from others with a more regulating framework. For example, Belgium, where conciliation (in fact mediation) is essentially mandatory, though not by law, however as an agreement among the social partners. And in the case of Spain, it is a full mandatory mediation. Or countries in which this process is voluntary but highly requested, such as Portugal where more and more parties are requesting conciliation and mediation to the competent public entity (DGERT).

In other countries the use of mediation is voluntary and mostly an exception (i.e. France, Germany). In some of these countries, mediation becomes mandatory only for certain sectors such as in case of a public transport strike (i.e. Italy). In these countries it has been found that mediation is culturally not internalized, and therefore, not a system that parties choose in cases of conflict. In Romania, conciliation is mandatory, however mediation is not. And while conciliation is relatively frequently used, in case this fails, few parties decide to go into mediation.

The issue of the mandatory mediation for collective labor issues continues being a debate in many countries. Parties recognize that ideally, the conciliation or mediation process starts with an authentic request of (one of) the parties, and the intention to negotiate an agreement, and not primarily because it is compulsory. This way, the parties show their engagement in the process and commitment to resolve the dispute using dialogue and cooperation (Foley \& Cronin, 2015). And in countries where mediation is-either by law or social agreement-mandatory, 
Table 15.2 Institutions organizing the collective mediation process in EC member states

\begin{tabular}{l|l}
\hline Country & Institution \\
\hline Belgium & $\begin{array}{l}\text { Ministry of Labor-Belgian Federal Public Service Employment, Labor } \\
\text { and Social Dialogue }\end{array}$ \\
\hline Denmark & Statens Forligsinstitution \\
\hline Estonia & National Conciliator Institution \\
\hline France & - \\
\hline Germany & - \\
\hline Italy & Prefecture \\
\hline Netherlands & $\begin{array}{l}\text { Joint Sectoral Committees (from the Social and Economic council), only } \\
\text { for conflict between Works Councils and employer. }\end{array}$ \\
\hline Poland & Ministry of Family, Labor and Social Policy. Social Dialogue Council \\
\hline Portugal & $\begin{array}{l}\text { Ministry of Work, Solidarity and Social Security. Directorate-General for } \\
\text { Employment and Labor Relations DGERT }\end{array}$ \\
\hline Romania & Ministry of Labor \\
\hline Spain & SIMA for Spain, SERCLA for the region of Andalucia \\
\hline United Kingdom & ACAS \\
\hline
\end{tabular}

parties do not always come to the table in good faith, however just to 'follow the ritual'. Nevertheless, for example the experiences in Spain show that mandatory mediation in this context resulted in a substantial reduction of social conflicts, and improvement of social relations (Martinez-Pecino, Munduate, Medina, \& Euwema, 2008). Finding a balance between mandatory and voluntary systems, such as the Model 3 (De Palo \& Trevor, 2016), might indeed also be relevant for many EC member states when regulating collective labor conflicts.

\section{(b) Providers of conciliation and mediation services and costs}

Table 15.2 shows the institutions providing conciliation and mediation services in each participating country. Most countries have a public institution for these services, who doesn't charge fees for the services related to collective labor conflicts. This can be either a special unit within the ministry of labor (e.g. Belgium, Portugal), or an independent organization funded by the government, such as the ACAS in the UK, or funded by regional governments in the case of Spain. Mediation service providers might also be funded by the social partners (unions and employer organizations), such as in the Netherlands (Joint Sectoral committees within the Social Economic council), or through collective memberships, as in Denmark (cooperative consultants). In some countries such as France and Italy, the government or corresponding prefecture manages the process of the collective conflicts that are mandatory for mediation (I.e. public transport sector). In Poland and Romania, the government provides the list of mediators for the parties to agree on the mediator. In Poland, both parties pay the mediation process equally. In Romania, while conciliation is free of charge, in mediation parties need to pay the mediator. In Germany there are no special pub- 
lic providers for conciliation or mediation services, as this is part of the collective negotiation process where social partners bring in higher levels to the conflict. In addition to these public provisions, which are mostly without costs for parties, there is a wide variety of private providers of consultation, conciliation and mediation. In some countries, for example the Netherlands, the market is more dominated by such private actors. These typically do charge fees to the parties. In several countries (Denmark, France, Germany, Italy, and the Netherlands) there is a growth of such private mediators in the market of collective labor conflicts. Also the markets for preventive actions (training, team development), and for rebuilding relations typically are open and free markets, where private consultants and mediators are active.

Looking at the costs of conciliation and mediation services, we see that in most participating countries there is some form of public or collective funding, which promotes access and use of the services. These are regulated for specific phases in the conflict, and in some countries also to specific sectors.

\section{(c) Who act as mediators}

In the countries where the ministry or another public institution manages the process, these institutions either employ directly the mediators, or work with a list of selected mediators. Being employed at such public institutes adds to the independent position of the mediator. Being a conciliator or a mediator is a full time function in some countries. We see this in the UK, where ACAS employs conciliators. ${ }^{1}$ And in Portugal, where a team of 11 mediators works dedicated to conflict resolution. These have specific qualifications, training, and coaching on the job. In Belgium we also see this dedicated role: civil servants who are part of the mediation unit combine different roles. These mediators, employed at the ministry full time, act as chairs of collective negotiations, however also in conciliation and in mediation procedures. Another example is Estonia, where the chairman of the labor dispute committee, an inspectorate official, and acts as a conciliator. Mediators here are public conciliators appointed also by the government. In Poland mediators are also public servants, however they also have their daily functions and on top of that they work as mediators when and where required.

The role of a conciliator or a mediator can also be integrated in other public functions. For example in France, where the labor inspector does the conciliation work, even if this takes only $1 \%$ of the workload. And in Italy, the regional prefects often act in the capacity of mediator. In Romania, mediators are also civil servants, however not necessarily trained or specially qualified in that capacity.

The second model for the use of mediators is working with a list of potential qualified mediators, who act on a case by case base, and typically do this as a side job. This for example is the situation in Spain (region of Andalucia), where both social partners, unions and employer organizations, provide a list of their "own" mediators. Here, mediation teams are always composed of mediators from these both sides, while a public official offers administrative support. The allocation of mediators to

\footnotetext{
${ }^{1}$ ACAS also provides an independent panel of well qualified mediators, and these services than are paid.
} 
specific cases is decided between the employer association and the main trade unions, not by the conflicting parties.

In Denmark the cooperation consulting units in charge of the mediation process also consist of a co-mediation team including members coming from the trade unions and of the employer associations.

Finally, another model is the free market model (the previous Model 1), where a variety of actors provide mediation services. In most countries this market is present, and conflicting parties can always hire such a mediator, if they agree to do so. In such cases, parties are free to select their mediator(s), and work as they prefer, also in preventive stages. Such practices are quite present in Germany and the Netherlands. In France there is a growing number of practitioners in the private sector, also offering training and coaching programs. In these countries, there is a very limited form of institutionalization.

In conclusion, in EC member states we can differentiate four basic profiles of mediators in collective conflicts. The first and most common profile is a public servant, who has part-time mediation functions, and is not specially trained in the conciliatory role. The second profile is the professional expert, who (almost) works full-time as conciliator and mediator, based in a national or regional mediation center. The third profile is the mediator who is representing employers' associations or trade unions, who acts incidentally, however is officially registered. The fourth profile is the independent expert, who is hired directly by the conflicting parties, outside any regulatory system. These people can be experts in labor law, negotiations, industrial relations, retired judges, or university professors, and acting at different phases and in different third party roles.

\section{(d) Conflict parties or representatives at the table}

In most countries parties act with agents in the mediation. For example, in an official conciliation process in Belgium, the mediator facilitates negotiations by representatives (typically sectoral professionals from employer organizations and unions. The conflicting parties are in separate rooms, and are consulted by the professional negotiators.

The advantages are evident, as professional negotiators are less personal and emotionally involved, and have a broader overview of options, and specific expertise and knowledge, for example on labor law. There is also a possible downside to this model. The parties are less engaged directly, and issues such as distrust, lack of communication and respect, which are often the root causes (see Chap. 2), are sometimes not dealt with in this format. Also, there is a potential agency problem, with the representatives having their own interests and agenda. Finally, representatives might experience strong pressures from their constituencies, who can literally 'stay in their room' (Munduate, Euwema, \& Elgoibar, 2012).

Another complexity, is that in many conflicts, employees are represented by different unions, not necessarily with the same interests at the mediation/negotiation table, and also even different employers, as occurs in joint-venture organizations or in organizations where some activities are externalized by temporary employment 
organizations. Such conglomerates of parties and interests generate a multi-party mediation which sets high demands for the coordination of the process and reaching an agreement. Such complex situations and systems require more training and mediators with a high level of competences in orchestrating the process.

An additional issue noticed in several countries is that not all relevant stakeholders are present. Particularly when the conflict is initiated at other levels, for example in the case of multinational companies, national governments or headquarters, or shareholders, who are not at the table. This can be illustrated by the challenges in Poland, where the conflicting parties appear at first to be the management and employees, however the manager in fact represents the interests of the (foreign) owner.

In many countries there is a tendency to promote direct communication between the main parties in an open dialogue. In that sense, mediation moves towards more informal conciliation processes. And only when these informal processes are not resulting in an agreement, further steps are taken, and representatives come more into play.

\section{(e) Mediating different types of conflict}

As discussed in Chap. 1, a classic distinction is made for two types of disputes-over interest or over rights. Indeed (see Table 15.1) in most EC countries, mediation is used for both types of conflict. Some countries, also outside the EC, limit formal mediation services to conflicts of interest. This might be due to the nature of the process, with conflicts of interest becoming evident when negotiations on collective labor agreements heat up.

From a technical point of view, disputes about interests have a greater potential to obtain integrative results, since the parties can create value in the negotiation and reach agreements that benefit both parties. Rights disputes are easier perceived by parties as a win-lose situation, and is about who is right and who is wrong. Parties have restrictions, given the fact that certain parameters are already agreed to in advance (Foley \& Cronin, 2015). The judicial system also exerts a detrimental effect on the mediation agreement to be understood by the parties as a feasible alternative (or BATNA). Based on the limited data on types of conflict in relation to agreements, we conclude that the agreement rate for rights conflicts is lower if compared to conflicts of interest. This is in line with previous research (Martinez-Pecino et al., 2008). It is important for mediators to recognize the different dynamics in these conflicts, and act upon these (Foley \& Cronin, 2015).

Disputes over rights and over interests are a very limited framing of the complex conflicts typically taking place. Throughout the studies in 12 countries, it is evident that when conflicts escalate, there are typically multiple issues at stake, and the underlying issues are usually driving the conflict. Issues over trust, communication, respect, insecurities, both in the relation between employees and the organization, and the employee representatives and (top) management, usually are more determinant for the conflict dynamics than the issue of 'rights' or 'interests' itself. Mediators therefore need the ability to address these underlying issues. 


\section{(f) Phase in which the system is activated}

Table 15.1 shows the phase in which the mediation system is activated. All participating countries describe that at the confrontation phase the system is already activated. During this phase competitive tactics are used by the parties and they are usually stuck in the conflict or using threats. Some of the countries, such as Belgium, Denmark or the United Kingdom activate the system already at an earlier stage, where tensions between parties are visible and there is a strong debate around the issues at the table. In Belgium, the mediator always facilitates the sectorial CLA negotiations, therefore monitoring conflictive issues also at early stages.

In Denmark and the United Kingdom, the system can be activated when the conflict of interests is still latent. The UK and Denmark have a fairly elaborated early conciliation system, aiming at direct support for parties in such early stages, working directly within the organizations. For example, such services are provided by SBI in the Netherlands (the expertise center for social dialogue), and by the Social Economic Counsel. Also, many private companies offer services for training and team development as preventive measures, however these are not part of a national public system.

\section{(g) How to mediate: from evaluative to transformative mediation}

The benefits of mediation as a problem-solving process is well demonstrated by the academic literature. In this process the mediator acts as facilitator for open dialogue and promotes interest based bargaining (Bollen, Euwema, \& Munduate, 2016; Carnevale \& Pruitt, 1992). Transformative mediation aims to develop the competences of the conflicting parties, and to contribute to a better mutual understanding and constructive relation.

Evaluative mediation, in which the mediator gives opinions and recommendations, is not congruent with the problem solving approach (Foley \& Cronin, 2015), and certainly not with the transformative approach (Folger \& Bush, 1996). The studies in each country presented in this volume suggest that mediators in quite some countries do use such an evaluative method of mediation. Here opinions and judgments on the positions and interests of the parties appear throughout the mediation. In some systems, evaluation by the mediators is considered a bias, and not recommended. Other systems have included proposals by the mediator team, generating a process similar to a non-binding mediation-arbitration procedure (MED-ARB). Here, the mediator offers a proposal to the parties, after a period of conciliation. A problem of evaluative mediation is that some of the parties may perceive that the impartiality has been lost, as in the case of Portugal, for example. In this sense, it would be interesting, as some systems do, (a) to regulate how and when it is appropriate to make recommendations, (b) how these recommendations should be, and (c) inform previously to the parties that they are participating in a process of mediation where the mediator might offer proposals, so that parties can give their consent to this.

Based on the evaluation of the systems, the recommendation is to use a problemsolving mediation for a medium-high intensity conflict level, whereas a more transformative mediation, based on improving communication, relations and understanding 
between the parties, could be more appropriate in the reconciliation phase. Evaluative mediation might be suitable when the conflict is at high-intensity level, with breakdown of communication and actions.

\section{(h) Measuring effectiveness}

It appears difficult to find reliable data in most countries on effectiveness. Registration of cases, including key characteristics, and outcomes of conciliation or mediation are often lacking. If these data are available, the measures are difficult to compare, and to interpret. Furthermore, effectiveness of mediation is not only to be measured by an agreement reached (Bollen et al., 2016). Satisfaction of parties with the agreement, likelihood of compliance with the agreement, and satisfaction with procedures and mediators, are also important indicators. These are mostly lacking. ACAS offers data, and also the different mediation providers in Spain present data on effectiveness. Generally, there is a strong need for more measures and more transparency on the outcomes of the efforts.

\subsection{How Is Mediation in Collective Labor Conflict Perceived by the Users?}

Here we have to differentiate between the evaluation of the mediation system, how the formal rules are arranged, the mediation procedures, and the mediators.

\section{(a) Evaluation of the system}

Users perceive that mediation is useful in producing new insights or common ground which in turn serve as a base for future negotiations. As an employee representative from Belgium mentioned: "The reconciliation committee is an essential stepping stone in the larger process of continuous social dialogue". In Belgium this has been explained by the active involvement of the mediator. This positive view is also shared by the employer representative: "...allows us to enter in a mechanism that renews the dialogue".

Also in Denmark, users perceive that the mediation helps to change the approach: "It was certainly not high flying, but it was just a boost for us to realize how to do things differently" (employer representative, Denmark). As the mediators were involved in early stage, the objective of the intervention aims to promote understanding of different interests and recreate trust. In that, users have a high degree of satisfaction. In the UK, trade union users believe that mediation allows them flexibility and autonomy.

In other countries with a low tradition of collective bargaining and mediation, as Estonia, users consider that the system needs to improve. Main reasons given are the lack of training, poor organization and lack of trust in outsiders. A user expressed: "As far as I understand it is hardly organized and structured. Many of the mediators do not have any kind of formal training". There exists also a lack of 
consolidated ADR culture and this process is mainly used in conflicts related to large sized organizations. In Poland, parties show ambivalence, in the sense that they see the potential as a value-creation activity, however question the current structures and quality. Also, users believe that mediation should be introduced at an earlier stage.

In Romania, users perceive that the system is dysfunctional and that the responsibilities are not clear, plus they consider that there is a lack of training in mediation-some recent training programs established aim to solve this view. However, they also share a general satisfaction with the conciliators-which is the mandatory step here-and with mediators-voluntary step. An employee representatives illustrates it the following way: "In Romania, trust and satisfaction with the conciliator and mediator exists when they are impartial and keep confidentiality". However, social partners critic the system. "It would be bizarre to claim lack of satisfaction with the efficiency of a specialist (employee of the Ministry) in a process that he solves admirably, only because the logic of the process is faulty".

The resistance towards the involvement of third parties is observed in many countries, such as France, Germany, Italy and the Netherlands. Larger organizations prefer to work often with an internal mediator, for example within the HR department. In Portugal users also prefer to negotiate directly without the intervention of third parties, however here parties appreciate the work and effort developed by DGERT. They also show a feeling of trust, given their neutrality.

\section{(b) Trust in the mediators by parties}

Overall a general climate of trust can be perceived from the parties towards the mediators. In several countries, as just mentioned, there are however serious questions about the competences of the conciliators or mediators. This is related to perceived lack of training, specialized expertise and status. Trustworthiness is generally strongly based in perceived competence, and this is an important condition for parties to engage in open information exchange and problem solving behaviors (Elgoibar, Euwema, \& Munduate, 2016; Foley \& Cronin, 2015). In countries with a more developed system, and high qualified mediators, this is reflected in trust in the mediators. A Portuguese employer concluded: "We have very competent and dedicated professionals and I have the best perception about them". Belgian social actors also believe that mediators are neutral and competent. In Spain (Andalusia) the cooperative model between employers and employees in the composition of the mediation teams, facilitates trust of the parties in the mediators' team. Also the users mention the importance of trust: "Trust in the mediators is key for successful mediations, experienced mediators who know the parties well achieve better results" (Employer representative, Spain).

ACAS in the UK is highly valued by its users for the integrity and professionalism of conciliators. In that, the long term relationship of the stakeholders with ACAS facilitates trust. ACAS follows an engagement policy and maintains contact with the parties during and after the conflict. When parties are voluntary searching for a mediator, trust is key, and based mostly on the mediators' reputation of competence, experience, benevolence and integrity, in line with literature (Elgoibar et al., 2016). 


\section{(c) Effectiveness of mediations}

Parties in most countries see a great potential for mediation in collective labor conflicts, though this is less the situation in France, Germany and Italy. However, in many countries, parties are critical on the current design features of the systems. This particularly is the case in countries where mediation is mandatory. Parties see here regularly the mediation as legally necessary, however not always useful, step. With parties following a ritual dance.

In the UK users perceive the system as effective, not only because it brings the parties back to the table, however also the process helps to manage the emotions of the parties involved. Managers and trade unions agree that the voluntarist approach is working and that this can be seen in the overall industrial relations climate. Apparently, organized (unionized) companies are perceived as more effective in terms of mediation process than the unorganized ones.

\subsection{How Is Mediation in Collective Labor Conflicts Perceived by Mediators?}

As we explain below the perception of the system changes considerably between mediators working (a) in cultures where the system is established and a tradition of mediation already exists and (b) in cultures where parties have difficulties to trust the system or where the benefits of using mediation is unknown by them. We focus on the satisfaction of the mediators with the system; the relation they build with the parties and their beliefs about effective behavior as mediators.

\section{(a) Satisfaction with the system}

Mediators in Belgium are satisfied with promotion and general familiarity with the system. This familiarity is linked to trust in the system, respect to the mediators and a higher understanding and respect to the agreement by the parties. However, they consider there is little follow up. Also, they consider the procedure is experienced as tiring and long and mediators fear that the budgetary restraints will bring more workload in the future. Also they believe that in the public sector the process is not effectively implemented and that media and politics have a strong influence.

In Portugal mediators are also satisfied with the legal structure and the fact that mediation is widely disseminated: "social partners are increasingly aware of the importance of DGERT and seeking our services more and more". These requests are mostly coming from trade unions, given that is this party the one who is dissatisfied with the conditions. In the UK mediators show high level of satisfaction with the system and with their work: "The value of our service is phenomenal...research suggests that for every pound ACAS spends on the service the economy saves $£ 80$." Acas Chief Conciliator UK.

This view differs in countries where the tradition of mediation is not existing. That is the case in France where there is no structured mediation system, and mediation 
is growing in the private sector but not as an institutionalize procedure. Also in Romania, even if the conflict resolution procedures available (conciliation, mediation and arbitration) are clearly defined and distinguished, mediators observe that parties confuse between them. Foley and Cronin (2015, p. 17) conclude that: "where there is no tradition (...) such a requirement may create, over time, an environment where parties come to understand the process and, in due course, to value it as a means to resolve disputes".

\section{(b) Relation with the parties}

In Belgium mediators shared that the fact that parties experience the process and are taken seriously by third parties is helping to reduce emotions and the intensity of the conflict. One important concern mentioned by Portuguese mediators is the confidentiality: "If parties don't feel at ease to speak freely, the negotiation won't be as fruitful". French mediators focus on the post-conflict service: "We need to be ready to go further in helping our clients deal with change and post-mediation if they need that help". In many countries such as Belgium, Romania and Poland, mediators share that they follow their own style. Some keep constant contact with the parties, while other keep distant.

Therefore, mediators differ in their approach to the relation with the parties, with some keeping distance and others having a closer relations, this can also depend on the type of mediation that each mediators follow (more transformative or more evaluative).

\section{(c) Effective behavior}

Proactivity, availability, trustworthiness, independence and impartiality are considered factors that contribute too the success of collective mediation. In the case of Belgium, mediators believe that empathy, active listening and paraphrasing are key. Mediators facilitate discussion and guard the process. The suggestions given should be minimal. This differs with Romania, where mediators are expected to share their opinion and suggestions.

Impartiality is seen as key to get trust "We jealously guard impartiality... because if we bias towards one side or the other our value goes out of the window" (Mediator, UK). Overall mediators as well as policy makers in the UK consider impartiality as the key for success. Also in Poland impartiality is relevant to be chosen by the parties to lead the mediation.

\subsection{Challenges for Conciliation and Mediation in Collective Labor Conflicts in Europe}

This paragraph explores the main challenges for conciliation and mediation that users and mediators have shared during the development of the project. 


\section{Lack of professionalization}

In several EC member states, conciliation and mediation is for many a part-time activity, with limited social and professional recognition. A deep analysis of the mediators and systems recommended a minimal regulation about the requirement that guarantees quality in mediation as occur in other professions (engineers or medicine among others), and a consolidated formative path. Mediators in many countries are requesting more training. A general way of getting trained is by joining mediations and learn from observation, before mediators lead their own process. The introduction of human resources practices in all the mediation systems is necessary, mainly in selection, training, and assigning of mediation cases, as well as systematic. The ACAS initiative to elaborate a mediation competence dictionary with instruments to measure the competence level could be a good practice for other systems.

\section{Institutionalization is needed}

This becomes an issue in countries as Italy where there are no institutions managing the process. Even in countries where the government leads the process there are critics on the way that this is established. The current situation is a consequence of the regulatory framework and the ways in which systems have been generating trust between the parties. In this sense, some countries have decided to generate systems where mediators belong to the parties, others prefer highly qualified professionals and others for assigning mediation tasks to their own civil servants. All of these systems may have a comparable effectiveness because they generate trust between the parties. In this sense, countries have to think about how to increase trust between parties and the mediation system.

Another challenge appears in those countries, such as Poland, where only a small part of the existing conflicts go to the mediation systems, which can generate enormous costs to the country's economy.

Making a comparative analysis, those more developed, and those that have still a low level of development, it is certainly worrying that countries with more than 20 million of inhabitants have less than thirty non-professional mediators. There is a high potential of evolution in the majority of the existing systems.

In some countries in which mediation is culturally not highly accepted, parties generally don't trust the system and therefore the promotion of mediation becomes really challenging.

\section{Restriction of time}

Mediation requires time, parties and mediators need to have enough space to explain their needs and generate integrative solutions. It is advisable not to have temporal control for mediation and that the time depends on the complexity of mediation.

\section{Measuring and evaluating effectiveness}

Poor social and administrative control of effectiveness has been concluded in most countries. Most systems have only agreement's indicators, and other satisfaction 
questionnaires that the parties voluntarily fulfill (with some methodological gaps). In this sense, a more systematic evaluation of the effectiveness of mediation according to the type of conflict would be necessary, even separating interest and right conflicts in more specific subtypes, as the ACAS does. It could also be interesting to analyze the effectiveness of mediation according to the type of organization (public vs. private; national vs. multinational). In the same way, these data should be analyzing to generate good practices in specific mediation situations or where there is little experience (e.g. mediation in the public sector, in multinational organizations, with lawyers, etc.). Discussions and workshops between mediators should help mediators to increase their effectiveness in all the systems.

\section{Flexibility in methods}

Mediation is not only a method of managing conflicts, but also where the parties negotiate in a less complex environment. For this reason, it is possible that the agreement could occur hours or weeks after the mediation session. In the same way, these spaces of sharing are very important to facilitate the social dialogue.

\section{Mandatory nature of the system}

Even if some countries share that the promotion of mediation is needed, in countries in which mediation is mandatory, experts emphasize that a number of disputes is subject to mediation not in order to aim for real agreement, but, in case of employers, to avoid being accused of breaking the law. In the case of the trade union side, to create an opportunity to undertake industrial and strike actions. Mediation, like negotiation, requires a minimum willingness of the parties to reach an agreement, which cannot be coerced or stimulated by any law.

\section{Use of representatives}

The fact that representatives act on behalf of the conflicting parties has the upside of de-escalating the conflict, but also the possible downside of reducing ownership, and commitment by the conflicting parties afterwards.

\subsection{Suggestions for a More Effective Collective Mediation System. What Can We Do?}

\section{Establishing a formal way of evaluating the procedures}

Mediators would like to get constructive feedback and shared experiences with the colleagues to learn from each other and gather the best practices.

\section{More time for each mediation}

Having more time available would allow the mediators as well as the parties to share more information and to use direct mediation in order to analyze the underlying conflict. 


\section{More mediators}

Some mediators have a very busy schedule, particularly in countries where mediation is compulsory. In that, a bigger team will help to divide the cases. In countries where mediation is not compulsory, mediators ask for more financial security and higher promotion of mediation.

\section{Formal and in-depth training}

Mediators in the participating countries suggest to program formal training of mediation and that this training is of quality and in depth. This also will increase the quality of the mediation process which can be linked to an increase of the social peace.

\section{Conflict prevention system}

Establishing a conflict prevention obligation by regular joint examination of danger signals in the social climate of the organizations.

\section{Extend the use of mediation in different phases}

As discussed in Chap. 1 the use of mediation should be extended to the first levels of intensity of conflicts and to the reconciliation phase (see Chap. 1). The challenge here is that even if a mediator could help when the conflict is still moderate, parties have a resistance to ask for third parties assistance and try to control the conflict themselves. In the same way, the restoration phase is considered as relevant to reconstruct the relationship between the parties with the active help of third-party expertise, engaging in post-reconciliation activities.

\section{Taylor-made interventions and more flexibility in the system}

Social partners require the ability of the process to respond to market changes. Some of the institutions are conservative and respond slowly to new demands or new types of organizations. The suggestion is a contingent model of mediation that allows mediators to decide about strategies and tactics they would use, based on scientific evidence.

\section{Promotion of the system}

Overall, mediators and users as well as policy makers recommend more promotion of the mediation system and its usefulness. Many companies and trade unions are still not aware or don't realize about the possible benefits of this alternative conflict resolution procedure. This is also linked to a lack of culture in ADR. The introduction of direct regulation on this issue is also suggested. Citing the authors of Chap. 10: "In Poland, to have the mediation wider applied a change in society is needed". We consider that this message can be extended to other participating countries. 


\subsection{Conclusion}

The mediation in collective conflict in Europe has generated heterogeneous systems explained by the regulatory framework of each country and by its social and political tradition in collective bargaining. The European Directive of mediation didn't include the labor setting, because it is a sector protected in some EU members by National States constitutional laws. As a consequence, systems are beginners, with a few professionalized processes.

The Member States have been guaranteeing the existence of mediation systems and supporting them economically and technically, understanding them as completely necessary for the country's economy and social peace. However, in order for the systems to fulfil their role in a more efficient way, the mediators must be further trained and professionalized, systems must be evaluated in order to learn and improve. An increase of the number of mediators is necessary. In the same way, greater emphasis is required on preventive mediation and on the reconstruction of relations between the parties when the conflict is over.

Acknowledgements The authors thank the Fundación Obra Social La Caixa for supporting this research work.

\section{References}

Bollen, K., Euwema, M., \& Munduate, L. (Eds.). (2016). Advancing workplace mediation through integration of theory and practice. Springer International Publishing.

Carnevale, P. J., \& Pruitt, D. G. (1992). Negotiation and mediation. Annual Review of Psychology, 43(1), 531-582.

Council of Europe. (1996). European Social Charter. Retrieved by https://www.coe.int/en/web/ european-social-charter.

De Palo, G., \& Trevor, M. B. (2016). EU mediation law and practice. Oxford University Press.

Elgoibar, P., Euwema, M., \& Munduate, L. (2016). Building trust and constructive conflict management in organizations. Springer International.

Eurofound. (2010). Right of collective bargaining. Brussels: European Union

European Commission. (2016). The implementation of the mediation directive. Directorate General for Internal Policies. Workshop 29th November 2016.

Foley, K., \& Cronin, M. (2015). Professional conciliation in collective labour disputes. A practical guide. International Labour Organization.

Folger, J. P., \& Bush, R. A. B. (1996). Transformative mediation and third-party intervention: Ten hallmarks of a transformative approach to practice. Conflict Resolution Quarterly, 13(4), 263-278.

Garriga, M. (2018). An European approach to mediation in collective conflict. Barcelona: University of Barcelona.

Martinez-Pecino, R., Munduate, L., Medina, F. J., \& Euwema, M. C. (2008). Effectiveness of mediation strategies in collective bargaining. Industrial Relations: A Journal of Economy and Society, 47(3), 480-495.

Medina, F. J., Vilches, V., \& Otero, M. (2014). How negotiators are transformed into mediators. Labor conflict mediation in Andalusia. Revista de Psicología del Trabajo y de las Organizaciones, $30(3), 95-100$. 
Munduate, L., Euwema, M., \& Elgoibar, P. (Eds.). (2012). Ten steps for empowering employee representatives in the New European industrial relations: New European industrial relations NEIRE handbook. McGraw Hill.

Valdes Dal-Re, F. (2003). Informe de síntesis sobre conciliación, mediación y arbitraje en los países de la Unión Europea. Conciliación, mediación y arbitraje laboral en los países de la Unión Europea, Ministerio de Trabajo y Asuntos Sociales, Madrid.

Yin, R. (2009). Case study research. Design and methods (4th ed.). California: Sage.

Open Access This chapter is licensed under the terms of the Creative Commons Attribution 4.0 International License (http://creativecommons.org/licenses/by/4.0/), which permits use, sharing, adaptation, distribution and reproduction in any medium or format, as long as you give appropriate credit to the original author(s) and the source, provide a link to the Creative Commons license and indicate if changes were made.

The images or other third party material in this chapter are included in the chapter's Creative Commons license, unless indicated otherwise in a credit line to the material. If material is not included in the chapter's Creative Commons license and your intended use is not permitted by statutory regulation or exceeds the permitted use, you will need to obtain permission directly from the copyright holder. 